\title{
Determinación de la longitud del surco presente en la Apófisis Oblicua del Primer Molar Superior Permanente
}

Determination of the longitude of the groove

present on the Apofisis Oblique of the

First Upper Molar Permanent.

Fecha de Recepción

|8 de agosto de $20 \mid$ |
Determinação do longitude do sulco

presentes no Apófisis Obliquo do

Primeiro Molar Superior Permanente.

\section{S. Discacciati de Lértora}

Profesora Adjunta Cátedra

Odontopediatría. FOUNNE.

M. G. Pared

Becaria de Posgrado Iniciación en Investigación. Secretaría General de Ciencia y Técnica.

Res. No I/15/09 .CS. UNNE

G. G. Bessone

Profesora Adjunta Cátedra Introducción a la Odontología. FOUNNE.

Lugar deTrabajo

Cátedra de Odontopediatría. FOUNNE

Avenida Libertad 5450.

Tel/Fax: 3794-57992.

Corrientes. Argentina.

Código Postal 3400.

\section{Resumen}

El Primer Molar Superior Permanente (PMSP) presenta la Apófisis Oblicua $(A O)$ que lo diferencia e identifica, reportándose la presencia de un surco que la atraviesa. El propósito de este estudio fue determinar la longitud del surco para su identificación definitiva. Se evaluaron superficies oclusales sanas, sin restauraciones ni anomalías, de 49 PMSP: 19 inertes y 30 presentes en boca de niños/as de 6 - 12 años, concurrentes a la Clínica de Odontopediatría. FOUNNE. Previo consentimiento informado, se realizó limpieza - secado de las superficies oclusales, observación directa e indirecta (modelos) y medición del surco con compás de punta seca y regla milimetrada, registrando según parámetros: Surco Corto (SC) hasta Imm; Surco Medio (SM) I - 2 mm y Surco Largo (SL) > 2 mm. Resultados: La longitud promedio en los PMSP inertes fue $1.7 \mathrm{~mm}$, predominando los SM (47.3\%) en tanto en los PMSP de niños/as fue $3.3 \mathrm{~mm}$, ostentando SL (100\%), siendo la longitud diferencial $1.6 \mathrm{~mm}$, mayor en los PMSP recién erupcionados. Conclusiones: En los PMSP el surco que atraviesa la $A O$ presenta una longitud promedio de $2.5 \mathrm{~mm}$, siendo tipificado como Surco Largo (SL), observándose que el paso del tiempo, influye en la características morfológicas del mismo.

\section{Palabras Claves}

Morfología - Estructura adamantina - Anatomía dentaria. 


\section{Abstract}

The First Upper Molar Permanent (FUMP) presents the Oblique Apophasis (OA) that the difference and identifies, reported the presence of a furrow that runs through it. The purpose of this study was to determine the length of the furrow for definitive identification. We evaluated occlusal surfaces healthy, without restorations or anomalies of 49 FUMP: 19 inert and 30 present in the mouth of children 6-12 years, concurrent to the Pediatric Dentistry Clinic. FOUNNE. Following informed consent, was cleaning - drying of the occlusal surfaces, direct and indirect observation (models) and measurement of the furrow with measure of dry point and down from rule, recording according to parameters: Short Furrow (SF) up to Imm; Median Furrow (MF) I - $2 \mathrm{~mm}$ and Long Furrow (LF) $>2 \mathrm{~mm}$. Results: The average length in the FUMP inert was 1.7 $\mathrm{mm}$, with a predominance of FM $(47.3 \%)$ in both in the FUMP of children was $3.3 \mathrm{~mm}$, wielding FL $(100 \%)$, being the differential length $1.6 \mathrm{~mm}$, more in the FUMP newly erupted, Conclusions: In the FUMP furrow that crosses the OA presents an average length of $2.5 \mathrm{~mm}$, being classified as Long Furrow (LF), while noting that the passage of time, influences the morphological characteristics of the same.

\section{Key Words}

Morphology - Structure adamantine - Dental anatomy.

\section{Resumo}

O Primeiro Molar Superior Permanente (PMSP) apresenta a Apófise Oblíqua (AO) que a diferença e identifica, relatou a presença de um sulco que atravessa o seu território. $O$ objetivo deste estudo foi determinar o comprimento do sulco para identificação definitiva. Avaliamos as superfícies oclusais saudável, sem restaurações ou anomalias de 49 PMSP: 19 inertes e 30 presentes na boca das crianças 6- 12 anos, concomitantes à Odontopediatria Clínica. FOUNNE. Após consentimento informado, foi limpeza - secagem da superficie oclusal, observação directa e indirecta (modelos) e medição do sulco com medida da regra, drypoint e sempre que o condutorsair gravação segundo os parâmetros: Sulco Curto (SC) até Imm; Sulco Mediano (SM) I - $2 \mathrm{~mm}$ e Sulco Longo (SL) $>2 \mathrm{~mm}$. Resultados: $O$ comprimento médio de PMSP inerte foi de $1,7 \mathrm{~mm}$, com uma predominância de SM $(47,3 \%)$ tanto no PMSP das crianças foi de $3,3 \mathrm{~mm}$, empunhar SL (100\%), sendo o diferencial comprimento $1,6 \mathrm{~mm}$, mais na MSPP irrompimento, Conclusões: No sulco PMSP que atravessa a $A O$ apresenta uma duração média de $2,5 \mathrm{~mm}$, sendo classificados como Sulco Longo (SL), registando embora que o passar do tempo, influencia as características morfológicas do mesmo.

\section{Palavras chave}

Morfologia - Estrutura diamantina - Anatomia dentaria.

\section{Introducción}

El Primer Molar Permanente (PMP), es el primer elemento dentario permanente que aparece en la cavidad bucal del niño, y se posiciona sin necesidad de reemplazar a otra pieza. Es por ello que en la mayoría de los casos su erupción pasa desapercibida'. Se presenta en número de cuatro (dos superiores y dos inferiores). Con su presencia transforma la oclusión primaria, en mixta.

Su configuración externa, ha sido descripta por varios autores, siendo los referentes más significativos Aprile, Figún y Garino². El Primer Molar Superior Permanente (PMSP) del mismo modo que el Primer Molar Inferior Permanente, presenta características morfológicas que le son propias y lo definen para su identificación ${ }^{3}$.

Según la literatura clásica ${ }^{4}$, la cara oclusal del PMSP, es de forma romboidal con cuatro cúspides (mesio vestibular, distovestibular, mesio palatina y disto palatina) que difieren entre sí en tamaño y altura, presentando además, dos fosas principales. De la fosa central parten un surco hacia vestibular $y$ otro hacia mesial, $y$ de la fosa distal emergen un surco hacia distal y otro hacia palatino. Las cúspides distovestibular y mesiopalatina están unidas por un puente de esmalte que cruza oblicuamente de palatino a distal, llamado Apófisis Oblicua, por la disposición que adopta 5 . Para identificar al PMSP, es fundamental observar la superficie oclusal del mismo, siendo el rasgo distintivo por excelencia, la presencia de la Apófisis Oblicua (AO) considerada exclusiva, 
tanto en dientes inertes como en dientes presentes en boca.

Bessone y colaboradores ${ }^{6}$, en un estudio realizado en PMSP inertes y naturales, reportan la presencia de un elemento anatómico no identificado por la literatura tradicional, ubicado en la estructura de la Apófisis Oblicua (AO), descripto como un surco pequeño que atraviesa dicha apófisis sin llegar a cortarla, denominando dicha estructura Apófisis Oblicua Tipo II (AO Tipo II) para diferenciarla de la Apófisis Oblicua sin surco, descripta por investigadores tradicionales, a la que llamaron Apófisis Oblicua Tipo I (AO Tipo I). Discacciati de Lértoray colaboradores ${ }^{7}$ en unestudio realizado en la Cátedra de Odontopediatría de la FOUNNE, observaron dicho accidente en las superficies oclusales de PMSP recién erupcionados, en niños escolares de 6 a 10 años, ratificando la presencia del surco como elemento anatómico, al considerar que en las piezas permanentes jóvenes, los accidentes anatómicos se encuentran libres de modificaciones fisiológicas y/o patológicas, condición que permite establecer con precisión la topografía presente.

Con la intención de aportar datos sobre el surco observado, se consideró necesario determinar la longitud de dicho elemento, a fin de identificar su estructura, de la cual sólo se conoce su presencia, siendo el propósito del presente trabajo determinar la longitud promedio del surco presente en la Apófisis Oblicua del PMSP.

\section{Material y Método}

El trabajo se realizó en las Cátedras de Odontopediatría e Introducción a la Odontología de la Facultad de Odontología de la UNNE.

Se estudiaron PMSP naturales inertes, pertenecientes a la Morfoteca de la Cátedra de Introducción a la Odontología de la FOUNNE y PMSP naturales presentes en boca, pertenecientes a niños de ambos sexos de edades 6- 12 años, pacientes de la Cátedra de Odontopediatría de la FOUNNE, autorizados por sus padres para el estudio, previa firma del Consentimiento Informado.

La muestra fue seleccionada por conveniencia evaluando un total de 49 PMSP: 19 piezas inertes y 30 piezas jóvenes, presentes en boca, utilizando como unidad de análisis la superficie oclusal de los mismos, siendo los criterios de inclusión:
PMSP con superficie oclusal sana, sin deterioro, libre de restauraciones, anomalías y/o lesiones. Una vez avalada la investigación por el Comité de Bioética de la Facultad de Odontología de la UNNE, se procedió a la realización de la misma. La metodología consistió en la preparación de las unidades de análisis y posterior medición de la longitud del surco a través del método directo e indirecto, según discriminación de las unidades de la muestra.

\section{Preparación de las Unidades de Analisis:}

Piezas dentarias inertes: Método Directo Las piezas dentarias, seleccionadas según criterios de inclusión, fueron colocadas en zócalos de cera, para soporte de las mismas durante la manipulación y posteriormente se procedió a acondicionarlas para la medición, cumpliendo los siguientes pasos: I.Limpieza de la superficie oclusal por medio de brochas en forma de copa de cerdas semiduras con pasta de piedra pómez y agua con baja velocidad. 2. Enjuague de la superficie con chorro de agua de canilla. 3 .Enérgico secado con aire impulsado por la jeringa de aire del equipo odontológico. 4. Observación y control del estado de las superficies. (Fig. IA)

Logradas las condiciones óptimas para el estudio, las observaciones se realizaron utilizando luz natural y lupa óptica (10x).

Piezas dentarias presentes en boca de los niños: Método Indirecto.

Se seleccionaron los PMSP de acuerdo a los criterios de inclusión establecidos. En las piezas elegidas se realizó una detallada profilaxis para eliminar placa bacteriana y detritus. Posteriormente se procedió a la toma de impresiones del PMSP seleccionado realizando los siguientes pasos: I. Selección de la cubeta parcial para la toma de impresión con alginato. 2. Prueba de la cubeta en boca. Recorte y adaptación de la cubeta si fuera necesario. 3. Remarginado de los flancos de la cubeta con cera utility. 4. Toma de impresión con alginato de fraguado rápido, teniendo en cuenta las especificaciones necesarias para la toma de impresiones en niños ${ }^{8}$ (Fig. IB). 5. Retiro de la cubeta. 6. Enjuague de la boca.7.Observación de la impresión previo lavado y secado de la misma. 8. Vaciado con yeso piedra. 9. Recorte y pulido del modelo.10.Obtención del modelo de estu- 
dio. (Fig. IC) Logrado el modelo aceptable, se realizaron las observaciones correspondientes, utilizando luz natural y lupa óptica ( $10 x)$.

\section{Medicion}

Las mediciones fueron realizadas con un compás de punta seca y regla milimetrada, procediendo de la siguiente manera: I. Localización del surco. 2. Colocación de una de las puntas terminales de los brazos del compás, en el extremo más alejado del surco, asentando con firmeza. 3. Apertura de los brazos del compás y colocación de la otra punta terminal en la fosa central, asentando en la misma. (Fig.2 Ay B). 6. Fijación de los brazos del compás en la medida obtenida. 7. Transporte de la medida obtenida a una regla milimetrada. (Fig.2 C). 8. Lectura de la medición alcanzada, expresándola en $\mathrm{mm}$.

Una vez obtenida la longitud del surco, se utilizó la Escala de Valoración de Surcos de Discacciati de Lértora MS (8) la que determina las siguientes estimaciones (Cuadro l).

Las observaciones, fueron registradas en una Tabla elaborada para tal fin, discriminando las variables: Dientes naturales inertes y Dientes naturales jóvenes presentes en boca de niños.

\section{Resultados}

En la muestra total (49 PMSP: inertes 19 y naturales 30 ), la longitud promedio del surco fue 2.5 $\mathrm{mm}$, correspondiendo dicha medida a Surco Largo (SL).

Discriminando según unidades de análisis, la Fig.3 demuestra que los PMSP Inertes presentaron Surcos Cortos, Surcos Medios y Surcos Largos, predominando los Surcos Medios(47\%) en tanto los PMSP presentes en boca de los niños, sólo presentaron Surcos Largos (100\%), como detalla la Fig.4

Respecto a la longitud promedio del surco el Cuadro II, demuestra que en dientes inertes, la misma fue de $1.7 \mathrm{~mm}$ y en los dientes en boca 3.3 $\mathrm{mm}$, existiendo una diferencia de $1.6 \mathrm{~mm}$ entre ambos grupos.

\section{Discusión}

La morfología dental, es un aspecto que sobresale como objeto de estudio de la antropología dental ${ }^{10} \mathrm{El}$ análisis de la morfología dental, se basa en la observación de la frecuencia y variabilidad de los rasgos morfológicos dentales coronales y radiculares (RDM) ${ }^{1.12}$. Los Rasgos Morfológicos Dentales Coronales (RDMC), se constituyen en formas fenotípicas del esmalte expresadas y reguladas por el genoma de un individuo y de una población durante la odontogénesis ${ }^{13}$.

Un rasgo morfológico dentario se constituye en un rasgo taxonómico elemental e indivisible reconocido como fen (unidad de variación fenética) $)^{14}$.Por lo tanto, para el análisis de los rasgos morfológicos dentales poblacional, se emplean RDMC estables y de alto componente genético, de los cuales se deberá establecer su gradación de variante o grado de expresión ${ }^{15}$.

El surco presente en la AO del PMSP no constituye un RDMC estable, por no presentarse en la totalidad de los casos, pero no obstante, es interesante su conocimiento y caracterización como aporte a los estudios morfológicos necesarios para poder identificar las piezas dentarias.

La muestra estuvo constituida por 19 piezas inertes y 39 piezas presentes en la boca de niños/as de ambos sexos y edades entre 6 y 10 años. A la observación directa, algunas piezas inertes, presentaron desgaste cuspídeo, bruñido de superficies adyacentes a la $\mathrm{AO}$ y otros signos de acción funcional, cuya variabilidad de la morfología hizo suponer que pertenecían a personas adultas ${ }^{16}$, en tanto las piezas presentes en boca, ostentaban la anatomía intacta, ofreciendo una mayor garantía a la observación de las estructuras morfológicas originales, teniendo en cuenta las expresiones de Thomas y col. ${ }^{17}$, quienes sostienen al describir las características anatómicas del PMP que, como toda pieza dental, la morfología varía con la edad, tanto en la estructura coronaria como en los conductos radiculares.

Los resultados del presente trabajo, por haberse realizado en piezas inertes $y$ en niños, observando PMSP recién erupcionados o con breve tiempo de permanencia en boca, demostraron las variaciones que se producen en las distintas edades, lo que brinda un aporte significativo a la caracterización del elemento anatómico en estudio. Las observaciones de las unidades de análisis ratificaron la presencia del elemento anatómico descripto por Guigliani y $\mathrm{col}^{18} \mathrm{como}$ un surco adamantino, reafirmando su presencia desde sus orígenes eruptivos en la cavidad bucal.

En cuanto a las mediciones, los valores regis- 

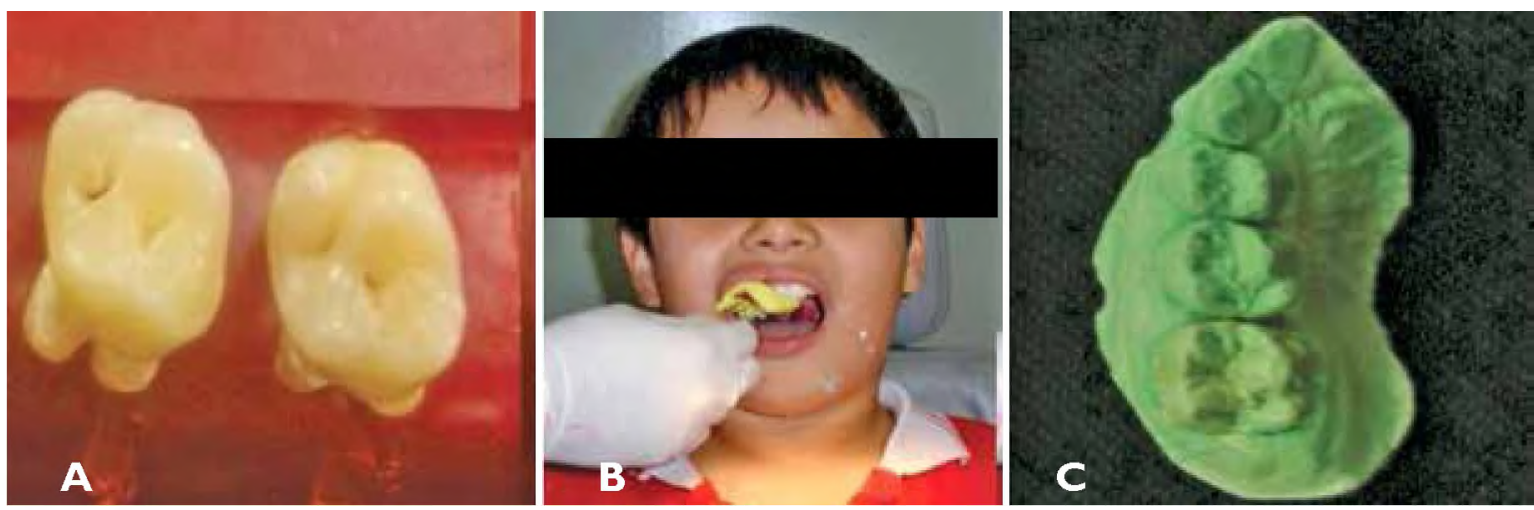

Figura I: Preparación de las Unidades de Análisis: A: Dientes Inertes. B: Dientes en boca: Toma de Impresión en niño. C: Modelo de estudio.
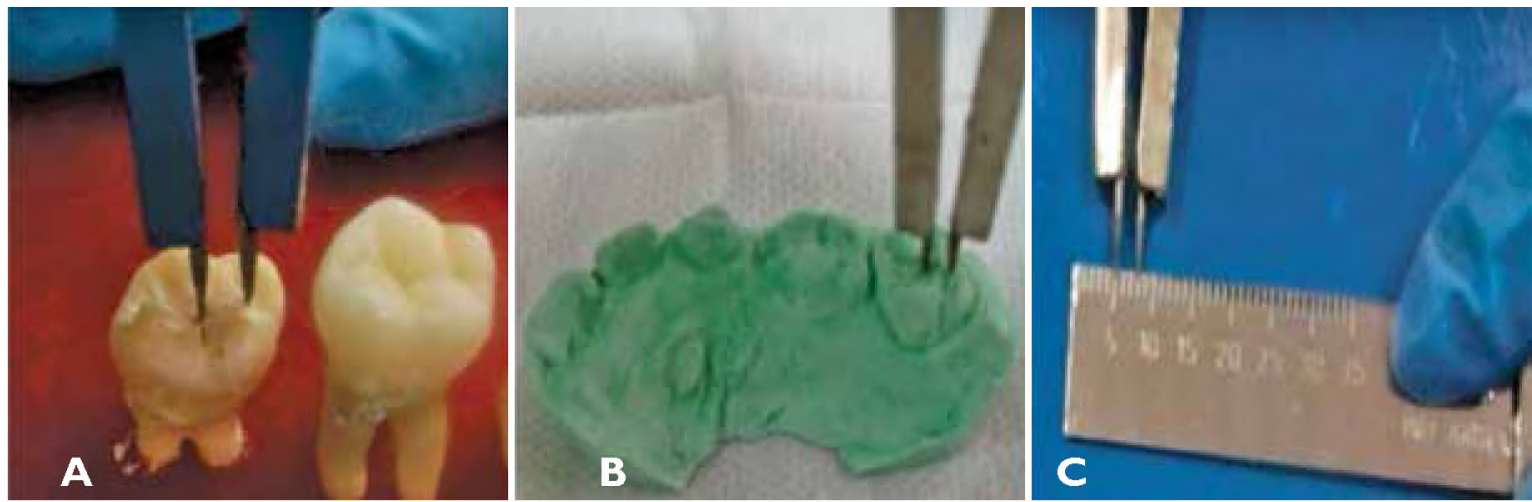

Figura 2: Medición: A: Dientes Inertes: Método Directo. B: Dientes en boca: Método Indirecto. C: Registro de Longitud.

Figura 3: Tipos de Surcos observados en PMSP Iner-

Tipos de Surcos observados en PMSP Inertes

$=$ Surco Corto $=$ Surco Medio $\equiv$ Surco Largo

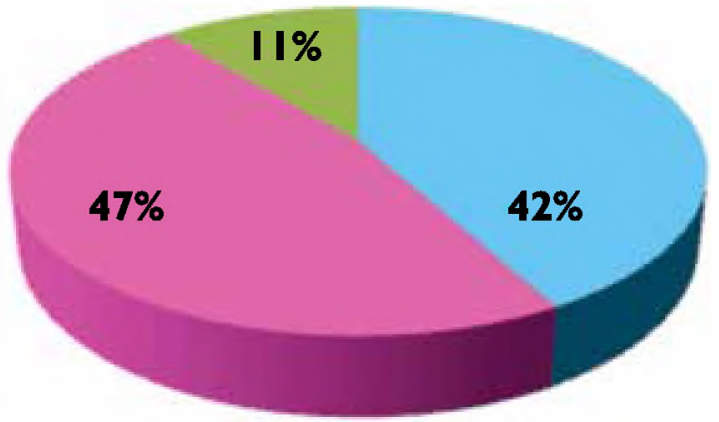

Figura 4: Tipo de Surco observado en PMSP en boca de los niños.

\section{Tipo de Surco en PMSP en boca de Niños}

$$
\text { -Surco Corto } \quad \text { Surco Medio }=\text { Surco Largo }
$$

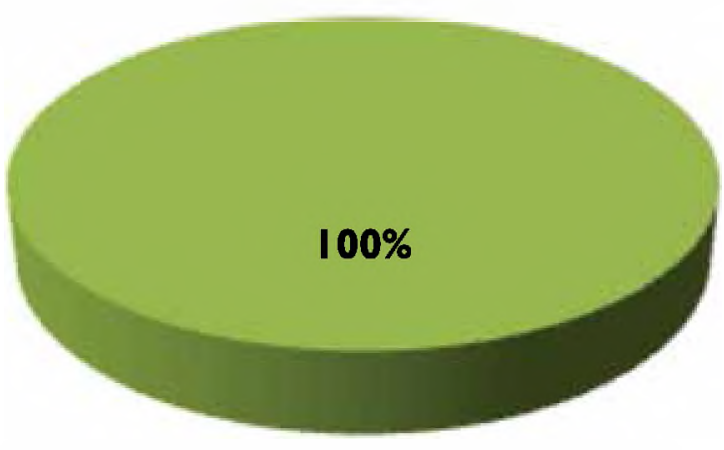


Cuadro I: Escala de Valoración de Surcos en Superficies Adamantinas.

\begin{tabular}{|c|c|}
\hline Tipo de Surco & Longitud \\
\hline Surco Corto (SC) & Hasta I $\mathbf{m m}$ \\
\hline Surco Medio (SM) & I a $2 \mathbf{~ m m}$ \\
\hline Surco Largo (SL) & Mayor a $2 \mathbf{m m}$ \\
\hline
\end{tabular}

Cuadro II: Longitud Promedio del Surco, según Unidades de Análisis.

\begin{tabular}{|c|c|}
\hline \multicolumn{3}{|c|}{ Longitud Promedio del Surco } \\
\hline PMSP Inertes & PMSP en boca (Niños) \\
\hline $1.7 \mathrm{~mm}$ & $3.3 \mathrm{~mm}$ \\
\hline \multicolumn{2}{|c|}{ Diferencia : $1.6 \mathrm{~mm}$} \\
\hline
\end{tabular}

trados determinaron la longitud promedio del surco, reportando un aspecto importante para su tipificación. En la muestra total (49), la longitud promedio del surco fue $2.5 \mathrm{~mm}$, valor que lo ubica como Surco Largo (SL).según Tabla de Ponderación utilizada (9). Los PMSP Inertes, presentaron diferentes longitudes, $y$ tipos de surcos: SC, SM y SL con predominio de los SM (47\%), siguiendo en frecuencia los $\mathrm{SC}(42 \%)$, con un bajo porcentaje de SL (I I\%). En tanto en los PMSP recién erupcionados o con poca permanencia en boca de los niños, no se observaron SC ni SM, sólo se registraron SL (100\%).

En los dientes inertes, el valor promedio de los surcos fue de $1.7 \mathrm{~mm}$, en tanto en los de la boca de los Niños, el valor promedio fue $3.3 \mathrm{~mm}$, demostrando una longitud diferencial de $1.6 \mathrm{~mm}$ entre ambos, menor en los surcos de dientes inertes. Las situaciones descriptas, ponen de manifiesto que cuando el PMSP erupciona con la AO Tipo II, el surco se manifiesta con medidas mayores a $2 \mathrm{~mm}$, correspondiendo a la tipificación de Surco Largo (SL) y en tanto y en cuanto el tiempo transcurre y los PMSP actúan y desarrollan su función (contacto propio de los impactos masticatorios, movimientos conformes al tipo de oclusión y los consecuentes desgates fisiológicos), dicho surco cambia sus características y alcanza medidas que lo tipifican como Surcos Medios(SM) y Surcos Cortos (SC). Estas apreciaciones, ponen de manifiesto que el paso del tiempo influye en los cambios morfológicos, según las observaciones registradas, coincidiendo con las estimaciones de Guatelli Steinberg ${ }^{16}$ y Thomas ${ }^{17}$, quienes valorizan en estos aspectos, la senescencia propia de la evolución biológica.

Este surco, por su condición de serlo, es un accidente anatómico que establece riesgo en relación a la retención de placa bacteriana y consecuentemente caries oclusales. Ekstrand ${ }^{19}$, refiriéndose a caries en los Primeros Molares Permanentes (PMP), expresa que el registro y cantidad de placa bacteriana muestra un patrón de ubicación preferencial, conforme a la macromorfología de las superficies oclusales, por lo que se considera que a mayor número de surcos, es mayor el riesgo desde el punto de vista anatómico.

En el caso particular de la AO Tipo II, no sólo se trata de la presencia de mayor número de surcos, sino que las observaciones realizadas demuestran que la depresión del surco descripto es perfectamente detectable permitiendo su fácil medición, resultando ser, un surco de magnitud apreciable. Se presenta con estas características desde su erupción en boca con medidas que lo caracterizan como Surco Largo (SL), de longitud significativa en cuanto a la retención de placa, lo que agrava el riesgo de padecer caries oclusales desde edades muy tempranas.

La importancia de estos hallazgos radica en tener en cuenta la presencia de este Rasgo Morfológico Dental Coronal (RDMC) a la hora de planificar 
acciones preventivas tempranas respecto a técnica y frecuencia de cepillado en las superficies oclusales y control de los nichos ecológicos por medio del sellado de surcos y fisuras presentes ${ }^{7}$.

\section{Conclusión}

En los PMSP el surco que atraviesa la $\mathrm{AO}$ (AO Tipo II), presenta una longitud promedio de $2.5 \mathrm{~mm}$, siendo tipificado como Surco Largo (SL),

En los grupos estudiados (PMSP inertes $y$ PMSP presentes en boca de niños), los valores promedios del surco, demuestran una diferencia de $1.6 \mathrm{~mm}$, mayor en los recién erupcionados, lo que demuestra que el paso del tiempo, influye en las características morfológicas del mismo.

\section{Bibliografía}

I. Discacciati de Lértora M.S; Lértora M.F: Primer Molar Permanente: Riesgo y Afecciones en sus primeros años. Comunicaciones Científicas $y$ Tecnológicas. Sec. Gral de Ciencia y Técnica. UNNE. Resumen extendido: www.unne.edu.ar. Año 2004.

2. Aprile, Figún M, Garino R: Anatomía Odontológica Funcional y Aplicada. El Ateneo. Argentina 2001.

3. Choquet F: Sistema Dentario en Figún, Mario E; Garino, Ricardo R. Anatomía Odontológica Funcional y Aplicada. El Ateneo 200I; 8: (242).

4. Rouviere $\mathrm{H}$ : Anatomía Humana, descriptiva, topográfica y funcional. Octava Edición. Madrid España, 1970: 77 - 78; 93 - 97.

5. Sobotta, J. Atlas de Anatomía Humana. Madrid. Médica Panamericana 2006.

6. Bessone G; Giglioni M. Detección Clínica de surco no tipificado en la cara oclusal del PMSP. Reunión de Comunicaciones Científicas y Tecnológicas de la UNNE. Año 2009.

7. Discacciati de Lértora MS, Bessone G, Mansutti F. Determinación de las características anatómicas no tipificadas, presentes en la Apófisis Oblicua del Primer Molar Superior Permanente. Rev. Facultad de Odontología de la UNNE. 2010; III (2): 15 - 20.

8. Discacciati de Lértora MS: Toma de Impresiones en Niños. Confección de modelos de estudio: Instructivo de las maniobras y técnicas para la toma de impresiones y confección de modelos de estudio en la atención Odontopediátrica. Pág: I - 35.Resolución N²12/99 C.D. FOUN-
NE. Cátedra de Odontopediatría. FOUNNE.

9. Discacciati de Lértora M.S: Determinación de la longitud del surco presente en la Apófisis Oblicua del Primer Molar Superior Permanente. Comunicación Científica. Jornadas de Comunicaciones Científicas y Tecnológicas de la Secretaría General de Ciencia y Técnica de la UNNE. Año 201I. Disponible en www.unne.edu. Ar/lnvestigación/com20 I I/M-000.pdf

10. Ocampo AM; Sánchez JD; Martínez C; Moreno F: Correlación de diez rasgos morfológicos dentales coronales entre molares deciduos y permanentes en tres grupos étnicos colombianos.Rev. Estomat. 2009; 17 (2): 7 - 16.

II. Moreno F; Moreno SM; Días CA; Bustos EA; Rodríguez JV: Prevalencia y Variabilidad de 8 rasgos morfológicos dentales en jóvenes de tres colegios de Cali. 2002. Colomb.Med 2004; 35(3 Supl I): 16 - 23.

12. Rocha L; Rivas H; Moreno F. Frecuencia y Variabilidad de la morfologia dental en niños afro-colombianos de una institución educativa de Puerto Tejada Cauca,Colombia. Colomb Med 2007; 38: 210 - 221.

13. Aragón N; Bastidas C; Bedón LK; Duque P; Sánchez M; Rivera S; Triana F; Noel Bedoya N; Moreno F: Rasgos Morfológicos dentales coronales en dentición temporal y permanente. Distancia Biológica entre tres grupos indígenas del Amazonas Colombiano. Revista odontológica Mexicana 2008; 12 (I): 13 - 28.

14. Rodríguez CD: La Antropología Dental y su importancia en el estudio de los grupos humanos. Rev.Fac.Odont.Univ.Ant.2005; 16(1,2): 52-59

15. Rodriguez CD; Delgado ME: Dental Anthropology. A brief definition. Inter. J. Dental Anthropol. 2000; I: 2 - 4

16. Guatelli Steinberg D.; Irish JD. Brief Communication: Early Hominin Variability in First Molar Dental Trait Frecuencies. AmJPhysAnthropol. 2005; I 28 (2): 477 - 484.

17. Thomas RP. ; Maule AJ. ; Bryant R.International Endodontic. Root canal morphology of maxillary permanent first molar teeth at various ages. Journal; 1993; 26 (5): 257 - 267.

18. Guiglioni M, Bessone GG: Estudio Macroscópico del esmalte en cortes seriados del Primer Molar Superior Permanente: Reunión de Comunicaciones Científicas y Tecnológicas de la UNNE. Año 2009.

19. Ekstrand KR.; Nielsen LA.; Carvalho JC; Thystrup AS. Dental plaque and caries on permanent first molar occlusal surfaces in relation to sagittal occlusion.Scandinavian Journal Dental Research. 1993; IOI (I): 9 - 15. 
FACULTAD DE ODONTOLOGIA

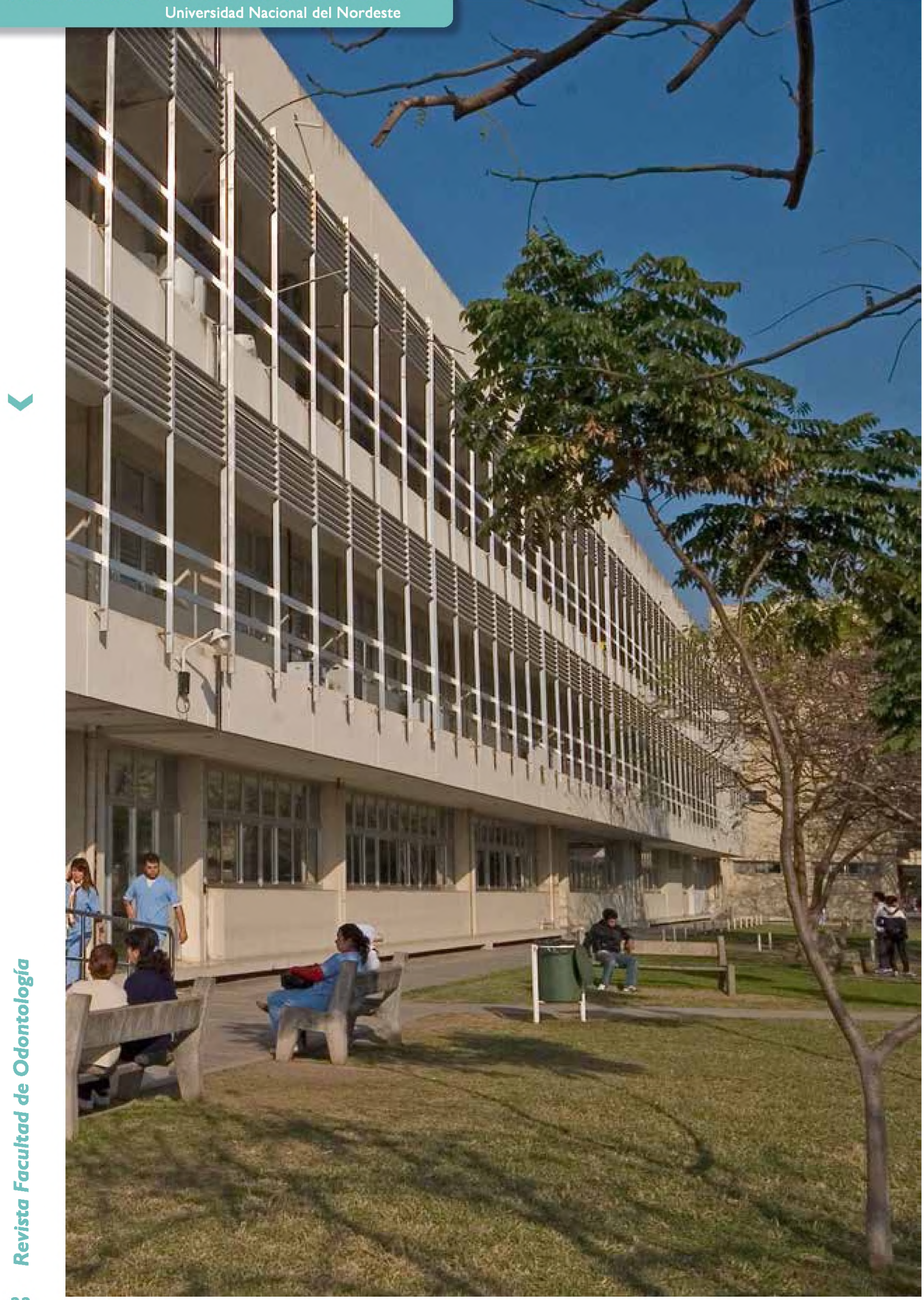

